\title{
The Moderating Effect of Gender on the Organizational Commitment-Rewards Relationship
}

\author{
Keisuke Kokubun ${ }^{1}$ \\ ${ }^{1}$ International Economy and Work Research Institute, Osaka, Japan \\ Correspondence: Keisuke Kokubun, International Economy and Work Research Institute, 3-14 \\ Kitahama-Higashi, Chuo-ku, Osaka, 540-0031, Japan. Tel: 81-6-6943-9490. E-mail: kokubun@iewri.or.jp
}

Received: May 13, 2017

Accepted: June 2, 2017

Online Published: June 7, 2017

doi:10.5539/ijbm.v12n7p1

URL: https://doi.org/10.5539/ijbm.v12n7p1

\begin{abstract}
This study investigates the relationship between rewards and organizational commitment (OC) of 9,826 Malay employees who work for 32 Japanese companies in Malaysia focusing on the difference between men and women. The result showed that delegation-related rewards (i.e. satisfaction with personnel evaluation and autonomy) had stronger influence on $\mathrm{OC}$ in male than in female employees. On the other hand, other delegation-free rewards (i.e. satisfaction with other treatments, fatigue, supervisor/co-worker support, training provision and role clarity) were equally related with $\mathrm{OC}$ for both genders. Discussions and implications concerning diversity and human resource management in the corporations in Malaysia are offered.
\end{abstract}

Keywords: exploratory factor analysis, gender, Japanese companies, Malaysian Malays, moderating effect, organizational commitment, rewards

\section{Introduction}

It is becoming an important theme to employ women because finding and keeping talented employees is becoming crucial in many countries (Antal \& Izraeli, 1993; Mattis, 2002; Vinas, 2003). Although, women have tended to stay in low positions with low-paying jobs while men have in many cases planed, organized, directed and controlled organizations (Curran, 2001; Carli \& Eagly, 2001), there is no evidence to suggest that women are less efficient than men as managerial leaders (Ismail \& Ibrahim, 2008). Furthermore, they are sometimes viewed more open to new ideas, better suited for teamwork, higher in qualities of listening and negotiating skills and more democratic than men (Eagly \& Johannesen-Schmidt, 2001; Vinas, 2003). In Malaysian setting, it is indicated that male managers tend to practice a commander style and female managers tend to portray a shepherd style (Roziah \& Maimunah, 2007), both of which have their own advantages in an organization (Ismail \& Ibrahim, 2008). Accordingly, many organizations today are trying to retain their female employees in response to regulations that call for equal treatment to genders.

Malaysia, an upper middle income country with per capita income of RM36,937 (US\$10,796), has long been committed to human development in areas such as poverty eradication, expansion of education and health facilities and, in 1991, set forth the national ambition of becoming a fully developed country by 2020 , economically, politically, socially, spiritually, psychologically and culturally. So far, Malaysia has obtained good results, for example achieved almost 100 percent literacy levels for both boys and girls. However, it is pointed out that there are nine areas in which Malaysia needs to improve, including the need to break social perceptions under presumptions of gender relations and social expectations. Besides, it is said that to improve gender equality, Malaysia needs better data capturing that is segregated by gender (United Nations Malaysia, 2016).

Furthermore, it is pointed out that women in Malaysia are socially, politically and economically disadvantaged and excluded from many areas of public and private life (Hutchings, 2000). Accordingly, in an organization, cultural beliefs and social responsibilities in Malaysia may not be exactly encouraging of promoting women into managerial positions (Grijins \& Velzen, 1993; Lim, 1993; Matsui, 1987; White, 1990). Supporting such assertion, previous research shows Malaysia's backwardness in various fields of gender equality. For example, in terms of the Gender Gap Index, an average of the inequalities between men and women in economic participation, education, health and political empowerment, Malaysia ranks 106th out of 144 countries, which is lower than most countries in the world but just above the rank of Japan's 111th. Although Malaysia obtained high scores at gender equality in wage and education enrolment, it showed low scores at gender diversity in labor force 
participation, managerial position, professional/technical works and parliament/ministerial positions. For example, at the national level, labor force participation rate for men and women were $81 \%$ and $52 \%$, whereas ratios of managerial positions were $78 \%$ and $22 \%$, respectively, indicating larger gender gaps in the volume and nature of workforce than most countries in the world (World Economic Forum, 2016).

In Malaysia, the situation of promoting elite professional women to leadership or higher managerial positions remains a sensitive issue that needs to be handled delicately due to unsolved barriers against women. Therefore, understanding the barriers that women face would help in creating a friendlier and more gender sensitive work environment (Ismail \& Ibrahim, 2008). However, many studies have indicated that career success of women depends on their ability to manage multiple roles as a wife, mother and worker (Hughes, 2004; Maimunah \& Ahmad, 1999; Maimunah \& Roziah, 2006) if there is no plentiful support from the organization they belong to. In such a condition, a company's success in women enrolment will primarily depend on how it can precisely capture the difference between men and women to create a workshop friendlier to the latter, although previous research in this area in Malaysia was not fully successful as described below. In this situation, the researcher considers that it is necessary to determine how companies can produce such environment in the workplace and attract the best female employees in Malaysia. So, this study analyzes antecedents of organizational commitment (OC), the strength of a person's attachment to the organization, and their differences between male and female employees who are employed by Japanese firms in Malaysia. The reason why the researcher focuses on the antecedents of $\mathrm{OC}$ is because $\mathrm{OC}$ is seen as a prime explanation for why some desire to remain employed while others do not (Allen \& Meyer, 1990; Mowday, Porter, \& Steers, 1982).

\section{Literature Review}

\subsection{Organizational Rewards in Malaysia}

The achievement of an organization does not only rely on how the organization utilizes its human capitals and competencies but also on how it incites commitment to the organization (Beukhof, De Jong, \& Nijhof, 1998). Barrett and O'Connell (2001) argue that employees may view some human resource practices as a reward. The result of this reward is that employees have a greater sense of debt, feel like insiders and are more committed to the organization. Besides, it was shown that enhancement of OC brings higher productivity and lower turnover intention (Buck \& Watson 2002; Meyer, Stanley, Herscovitch, \& Topolnysky, 2002; Steers, 1977).

Several studies conducted in Malaysia also show that OC is strongly related to the employee's intention to leave or stay with the organization and it plays a vital role to strengthen the organization growth (Leow \& Khong, 2009; Rachagan, Tong, Terpstra, \& Mahenthiran, 2014; Salleh, Nair, \& Harun, 2012). In addition, another study has indicated a strong link between job satisfaction and organizational commitment (Samad, 2007). The rewards statistically correlated with $\mathrm{OC}$ in previous study in Malaysian setting were: financial compensation (Govindasamy, 2009; Ibrahim \& Boerhaneoddin, 2010; Kee, Ahmad, \& Abdullah, 2016; Normala, 2010); autonomy or discretional power (Govindasamy, 2009; Karim, 2010); support from supervisors/ collegues (Aghashahi, Davarpanah, Omar, \& Sarli, 2013; Lo, Ramayah, \& Min 2009; Marmaya, Hitam, Torsiman, \& Balakrishnan, 2011; Normala, 2010; Ramli \& Desa, 2013); training or skill/ ability provision (Bashir \& Long, 2015; Govindasamy, 2009; Juhdi, Pa'wan, \& Hansaram, 2013; Normala, 2010); role clarity (Karim, 2010), etc. Besides, although not tested as an antecedent of OC in previous research, it is suggested there is a relationship between emotional exhaustion and $\mathrm{OC}$ in Malaysia because average working hours per week had increased as a result of economic growth and industrialization and Malaysian employees had reported that they are stressed under heavier workloads (Manshor, Fontaine, \& Chong, 2003).

Although these studies much contributed to understanding of OC in Malaysia, it is unclear how different categories of organizational rewards might influence $\mathrm{OC}$ of different genders in this country. The present study is the first to research the difference between men and women in relationship between OC and various rewards using the sample of male and female Malays who work for Japanese companies in Malaysia. This should enable us to advise managers who work for companies in Malaysia as to what strategies may be utilized to foster high levels of OC amongst female employees and create workplaces of high diversity.

\subsection{Moderating Role of Gender}

According to Elizur and Koslowsky (2001), one of the most popular demographic variables studied in the work value or behavioral construct is gender as it is known that men and women have different behavioral tendencies. Accordingly, past studies have shown the existence of some difference in OC between men and women (Hartmann, 2000; Marsden, Kalleberg, \& Cook, 1993; Mason, 1995; Wiersma, 1990; Mathieu \& Zajac, 1990; Savery \& Syme 1996) indicating some differences in the mechanisms of OC. Actually, gender is also found to act as a moderator in the study of OC (Elizur \& Koslowsky, 2001; Mellor, Mathieu, \& Swim, 1994). However, 
gender was not significant as a moderating variable in previous study of knowledge workers in Malaysian setting, suggesting that the relationship between rewards and OC may not be affected by gender in some situation (Govindasamy, 1999). However, this result may not be generalized as women in high-level positions tend to be as masculine as men and accordingly more masculine than women in lower level positions adapting themselves to a male-oriented workplace to become as capable as their male counterparts (Ledet \& Henley, 2000). In such a condition, it may not be enough just to compare men and women in particular positions to test the role of gender as a moderator in an entire organization.

In line with this, it is said that the cultural association of power and authority with masculinity makes it difficult for women to hold positions of power because their gender identity contradicts the current male-centered organizations (Charles \& Davies, 2000). Another research shows that the pressure that women face in balancing career and family is the most significant barrier in women's attempt to advance in the society (Rosser, 2004; Maskell-Pretz \& Hopkins, 1997; Miller, 2004). Furthermore, previous research in Malaysian setting revealed that not a small number of female employees considered that women in general have to work harder and longer to prove their credibility in order to achieve the same progress with men and faced difficulties to take time off as a company expects them to put the work first, making execution of work-life balance policy difficult (Ismail \& Ibrahim, 2008). Since the workplace is discriminatory, to succeed in their careers women in Malaysia must try to overcome such obstacles as the reluctance of male employers to recruit women, uncooperative male peers, male-oriented working conditions, and the lack of women role models (Mansor, 1994).

So, the present research should like to propose a new hypothesis to be tested: The reason why important posts in a workplace tend to be dominated by men in a society of masculinity is because there are some rewards different in strength of relation with OC between men and women. The mechanism of this hypothesis will be explained by the following manners: (i) there are two kinds of rewards, delegation-related rewards and delegation-free rewards; (ii) delegation-related rewards are the ones which become larger in its amount or range as authority is delegated to the employees, such as rewards related with personnel evaluation (e.g. salary, position, promotion, evaluation, etc.), autonomy at the work, etc; (iii) delegation-free rewards are the ones which do not differ by the extent of empowerment, such as rewards not directly related with personnel evaluation (e.g. welfares, holiday, working hours, etc.), support from supervisors and co-workers, training, role clarity, health control, etc; (iv) delegation-related rewards are not as strong incentives for a women as for a men to strengthen OC because the work-life balance may be sacrificed if she accepts such rewards together with more discretionary works; (v) on the other hand, delegation-free rewards are as strong incentives for women as for men because such rewards do not request her to bear the work of high responsibility abandoning a part of her traditional roles as a woman.

In short, delegation-related rewards (i.e. 'satisfaction with personnel evaluation' and 'autonomy' by the terms of this research) are considered to be the main accelerators of molding male-dominated organizations due to the difference of magnitude between men and women on responses to these rewards. At a workplace of more masculine culture, women may not respond to these rewards as much as men do because they have to accept male working styles giving higher priority to the work than to domestic duties in exchange of higher treatment and authority. This hypothesis is also in line with an assertion that organizations' goal-oriented and aggressive culture may lead to women opting out of management and choosing to remain at lower levels (Cecila \& Shanti, 1999). Actually, in Malaysian setting, it is observed that a large number of women, particularly Malays, often ignore promotion prospects and choose to maintain the position they occupy rather than intensifying family conflict of their own feelings of guilt regarding their children (Women for Women Foundation (Asia), 1990). On the other hand, delegation-free rewards (i.e. 'satisfaction with other treatments', 'fatigue', 'supervisor/co-worker support', 'training provision' and 'role clarity' by the terms of this research) are not considered to boost forming of men-dominated workplace as they are important alike for both genders and not accompanied by larger responsibilities which have to be incurred. For example, welfare such as medical care, social events, etc. and facilities, such as parking areas, canteens, etc., may be perceived as rewards for the employees to reciprocate in the manner of high commitment to the company, but may not be accompanied by a feeling of obligation to adapt to masculine corporate culture as they are the ones neutral and given to employees irrespective of their positions in the company. Off course, the same story may be applicable to more women-related rewards such as maternity allowance or leave, etc. as they are commonly provided irrespective of her position. This leads us to the following hypotheses:

\section{Delegation-related rewards}

Hypothesis 1: Relationship between satisfaction with personnel evaluation and OC is positively stronger for men than women. 
Hypothesis 2: Relationship between autonomy and $\mathrm{OC}$ is positively stronger for men than women.

\section{Delegation-free rewards}

Hypothesis 3: Relationship between satisfaction with other treatments and $\mathrm{OC}$ is equally strong (weak) for men and women.

Hypothesis 4: Relationship between fatigue and OC is equally strong (weak) for men and women.

Hypothesis 5: Relationship between supervisor support and OC is equally strong (weak) for men and women.

Hypothesis 6: Relationship between co-worker support and $\mathrm{OC}$ is equally strong (weak) for men and women.

Hypothesis 7: Relationship between training provision and $\mathrm{OC}$ is equally strong (weak) for men and women.

Hypothesis 8: Relationship between role clarity and $\mathrm{OC}$ is equally strong (weak) for men and women.

For reference, a recent empirical research in setting of Thailand by Kokubun (2017) shows that the rewards which appear in the hypotheses above are associated with OC, although they are classified differently into extrinsic (benefit satisfaction; fatigue), intrinsic (autonomy; training; role clarity) and social (supervisor support; co-worker support) rewards. Here, Porter and Lawler (1968) defined intrinsic rewards as the satisfaction that a person derives from doing the job and extrinsic rewards as tangible benefits obtained as a result of doing the job, such as pay and promotions. On the other hand, according to Mottaz (1985), social rewards refer to those that are derived from interpersonal relationships with colleagues and supervisors. There is growing evidence to suggest that organizations can enhance the commitment of their workforce through the provision of these rewards (Newman, Thanacoody, \& Hui, 2011). This is in line with the 'social exchange theory' which supposes that when an individual is happy with the rewards provided by their organization, they will reciprocate by developing positive attitudes towards their organization such as higher levels of commitment (Haar, \& Spell, 2004). Furthermore, it was shown that enhancement of OC brings higher productivity and lower turnover intention (e.g. Meyer, Stanley, Herscovitch, \& Topolnysky, 2002). Accordingly, main contribution of this research is providing new hypotheses and conducting the tests regarding gender differences in OC-rewards relationship by modification and application of such a series of previous research.

\section{Methods}

\subsection{Participants}

We sent questionnaires to employees in 32 Japanese companies in Malaysia. We purposely selected Japanese companies in Malaysia instead of other kinds, such as state-owned or other private companies as they are considered to have a different set of HRM practices and may possibly influence the results in a manner difficult to be controlled. 25,000 questionnaires were distributed via the HR department of participant companies. The participation was basically compulsory irrespective positions or departments they belong to as previous research suggests that women in various job positions do not differ in their perceptions with regard to barriers they face for career progression (Ismail \& Ibrahim, 2008). With a promise to present the summary results, the HR department of each firm administered the questionnaires by distributing and collecting completed questionnaires. Each respondent was requested to put the completed questionnaire into an envelope that the researcher provided along with the questionnaire and seal it for him/her self to guarantee perfect anonymity. Overall, 22,206 surveys were collected, reflecting a response rate of $88.8 \%$. We eliminated 12,380 surveys due to missing values or inappropriate participants for this research (e.g. Chinese, Indians and other ethnic groups, contract employees, foreign workers, Japanese expatriates, etc.). The reason why the researcher selected Malays only is because: there are some differences on motivating factors among ethnic groups (Islam \& Ismail, 2008); what is deemed acceptable behavior and responsibilities for women differs markedly among ethnic groups (Hutchings, 2000); it is indicated that Malays face larger barriers against career advancement than other groups due to tradition and religion they follow (Siraj, 1984). Accordingly, limitation of the research target to Malays, an ethnic group with the largest population in Malaysia, is considered to be reasonable to facilitate precise interpretation of the results. Consequently, the final samples comprised 9,826 Malaysian Malay participants, where 5,225 or 53.2\% are men and 4,601 or $46.8 \%$ are women. They are abstracted from the states of Selangor (13), Penang (6), Johor (5), Kedah (4), Kelantan (1), Perak (1), Kuala Lumpur (1) and Negeri Sembilan (1), respectively (the figures in parentheses are the number of companies). $4.3 \%$ of men and $0.7 \%$ of women were at managerial positions. Other demographic information of the participants is shown in the tables of appendix. We controlled for all the demographic variables in order to attenuate any concern about sample compatibility.

\subsection{Measures}

Most questions used at this research are developed by IEWRI (1996) and later adopted by Kokubun (2006). 
IEWRI, International Economy and Work Research Institute, is a research institute which is located in Osaka and conducts employee opinion surveys for members of trade unions of more than 300 representative Japanese companies and give them practical advises to activate their organizations and enhance corporate productivity based on the survey results and the theory of social psychology with supports from university professors and researchers (http://www.iewri.or.jp/). The main reason why the researcher use IEWRI's questions is because this research is also designed and initiated to provide advices on how to enhance the commitment or motivation of local employees to the management of Japanese companies located in foreign countries. Secondary reason is that IEWRI has rich opinion database of Japanese employees who work for Japanese companies obtained by similar way of this research, which is considered to be used for international comparison in future research. The original questionnaire was developed in English and then translated into Bahasa Malaysia (Malaysian national language). To ensure the accuracy of the translation, the questionnaire was then translated back. All the questions are written in English and Bahasa Malaysia so that a respondent can chose the familiar one according to its origin.

\subsubsection{Satisfaction with Personnel Evaluation}

Satisfaction with personnel evaluation was measured on a four-item scale developed by IEWRI (1996). The items were measured on a five-point scale that ranged from 1 (dissatisfied) to 5 (satisfied). The alpha reliability was 0.763 and 0.711 for men and women, respectively.

\subsubsection{Satisfaction with Other Treatments}

Satisfaction with other treatments was measured on three-item scale developed by IEWRI (1996). The items were measured on a five-point scale that ranged from 1 (dissatisfied) to 5 (satisfied). The alpha reliability was 0.767 and 0.768 for men and women, respectively.

\subsubsection{Fatigue}

Fatigue was measured on a five-item scale developed by IEWRI (1996). The items were measured on a five-point scale that ranged from 1 (incorrect) to 5 (correct). The alpha reliability was 0.829 and 0.809 for men and women, respectively.

\subsubsection{Supervisor Support}

Supervisor support was measured on a six-item scale originally developed by Kokubun (2006) using Eisenberger, Huntington, Hutchison and Sowa (1986) as reference, except an item 'My boss/supervisor gives me sufficient information about the management policy of the company and the division' which was originally developed by IEWRI (1996). The items were measured on a five-point scale ranged from 1 (I don't think so) to 5 (I think so). The alpha reliability was 0.857 and 0.836 for men and women, respectively.

\subsubsection{Co-worker Support}

Co-worker support was measured on a four-item scale developed by IEWRI (1996). The items were measured on a five-point scale ranged from 1 (dissatisfied) to 5 (satisfied). The alpha reliability was 0.791 and 0.815 for men and women, respectively.

\subsubsection{Autonomy}

Autonomy was measured on a four-item scale developed by IEWRI (1996). The items were measured on a five-point scale that ranged from 1 (I don't feel so) to 5 (I feel so). The alpha reliability was 0.644 and 0.678 for men and women, respectively.

\subsubsection{Training Provision}

Training provision was measured on a two-item scale developed by IEWRI (1996). The items were measured on a five-point scale that ranged from 1 (I don't think so) to 5 (I think so). The alpha reliability was 0.619 and 0.629 for men and women, respectively.

\subsubsection{Role Clarity}

Role clarity was measured on a two-item scale developed by IEWRI (1996). The items were measured on a five-point scale that ranged from 1 (I don't think so) to 5 (I think so). The alpha reliability was 0.534 and 0.533 for men and women, respectively.

\subsubsection{Organizational Commitment}

Five items were used to measure OC. Three items were adopted from IEWRI (1996) to which two additional items were added. Two additional items were 'I have strong will to work hard in this company' and 'I am willing to contribute to development of this company'. The items were measured on a five-point scale that ranged from 1 
(I don't think so) to 5 (I think so). The alpha reliability was 0.779 and 0.746 for men and women, respectively.

\subsubsection{Control Variables}

Several demographic variables were included to control for individual differences. Answered figures without any conversion were used for age and organizational tenure. Sample dummy shows men or women. Educational background, turnover experience, marital status, indirect/direct department and managerial/non-managerial position were also measured. Thirty one dummy variables were created to control for the thirty two different companies.

\section{Results}

\subsection{Analysis}

We conducted an exploratory factor analysis of all items (except control variables) to examine measurement invariance between men and women. The results of the factor analysis with varimax rotation are presented in Table 1, confirming a nine-factor solution for all the items of satisfaction with personnel evaluation, autonomy, satisfaction with other treatments, fatigue, supervisor support, co-workers support, training provision, role clarity and OC. The factor structure was the same for men and women; therefore, we are convinced that both men and women ascribed the same meanings to the scale items used in the current study (Milfont \& Fischer, 2010).

Descriptive statistics for men and women are presented in Table 2. We tested our hypotheses using hierarchical regression analysis. We entered the control variables in Step 1 and main effects of satisfaction with personnel evaluation, autonomy, satisfaction with other treatments, fatigue, supervisor support, co-workers support, training and role clarity in Step 4. In Step 5, we entered sample variable (1 for men and 0 for women) and its interaction terms with main effects for the entire sample to test gender moderation. Variables forming the interaction term were entered to minimize multicollinearity among the interaction terms and their components (Akien \& West, 1991). In Step 2 to 3, main effects were separately entered by the kind of rewards (delegation-related and delegation-free rewards) to test their comparative importance. In addition, we conducted separate regression analysis using male and female samples. All regression results are presented in Table 3.

Step 1 presents the results when only the control variables are included in the regression to predict OC. Five out of seven demographic variables were found to influence OC positively. They are: age, turnover experience indirect department and position, which mean that older, indirect, at a managerial position who experienced other companies tend to have higher OC than others. On the other hand, university graduate was negatively associated with OC, which means university graduates tend to have lower OC than others. Other demographic variables, tenure and marital status have no significant relationship with OC.

Step 2 presents the results when two variables of delegation-related rewards are added to the regression. Likewise, Step 3 presents the results when six variables of delegation-free rewards are added to the regression. All the eight reward variables except fatigue were significantly associated with OC. Observing Adjusted $\mathrm{R}^{2}$, delegation-related and delegation-free rewards explained $21 \%$ and $31 \%$ of additional variance in OC, respectively. The number of composing rewards included implies that delegation-related rewards are more important than delegation-free rewards for OC.

Step 4 presents the results when all the eight reward variables are added to the regression. All the variables except fatigue are positively associated to the regression significantly $(p<0.01)$. On the other hand, fatigue is positively but insignificantly associated $(\beta=0.01, \mathrm{p}>0.05)$.

Step 5 presents the results how the variables are moderated by the sample. The relationship between satisfaction with personnel evaluation and $\mathrm{OC}$ was moderated by the sample, showing that their relationship was stronger for men than women $(\beta=0.10, p<0.01)$. In other words, male $\mathrm{OC}$ was affected more by satisfaction with personnel evaluation compared with female. Likewise, the relationship of autonomy with OC was positive and stronger for men than women $(\beta=0.09, \mathrm{p}<0.01)$, which suggests that autonomy is more important in forming OC for men than women. The significant results of these moderation tests are consistent with Hypothesis 1 and 2. In other words, delegation-related rewards (i.e. personnel evaluation and autonomy) are more important predictors of OC for men than women.

On the other hand, the relationships of other variables, satisfaction with other treatments, fatigue, supervisor / co-worker support and training provision, with OC were not moderated by the sample, showing that their relationships were equally strong (weak) for men and women. These results are consistent with Hypothesis 3,4 , $5,6,7$ and 8 .

For reference, 'continued' tables are the ones men and women are separately analyzed. All the eight reward 
variables were significantly associated with $\mathrm{OC}$ except for fatigue of both genders and satisfaction with personnel evaluation of women. Observing Adjusted $\mathrm{R}^{2}$, delegation-related and delegation-free rewards explained $23 \% / 30 \%$ and $16 \% / 30 \%$ of additional variance in OC of men/women, respectively. This implies three important points: (1) both types of rewards are important for OC of both men and women; (2) delegation-related rewards (per component) are more important than delegation-free rewards for OC of both men and women; (3) delegation-related rewards are more important for $\mathrm{OC}$ of men than of women; (4) delegation-free rewards are equally important for OC of men and women; (5) comparatively, delegation-related rewards are more important for men than for women, whereas delegation-free rewards are more important for women than for men.

\subsection{Discussion and Implications for Theory and Practice}

The present study contributes to the literature showing that, in line with previous works, gender is an important factor to determine antecedents of organizational commitment (OC) (Mellor et al., 1994; Elizur and Koslowsky, 2001). Specifically, it highlights three differences and similarities between the factors that enhance the OC of male and female Malay employees working in Malaysia.

First, compared to women, men typically respond more positively to the existence of delegation-related rewards, namely rich personnel evaluation and autonomy in the workplace. In other words, male employees may respond more easily to such rewards and have higher OC. This may be because a workplace tends to have a culture of masculinity or traditional gender division of labor shared by employers and employees, which leads people to expect domestic responsibilities to be women's primary roles and frees men from domestic and childcare responsibility at home (Charles \& Davies, 2000). In response to this situation, women sometimes have to reduce their time in the workplace even if depressed wages and lack of advancement accompany that choice (Williams \& Cooper, 2004) because the pressure that women face in balancing career and family is the most significant barrier in women's attempt to advance in an organization (Rosser, 2004; Maskell-Prets \& Hopkins, 1997; Miller, 2004).

This result provides us important implication to consider why major posts of modern organizations are dominated by men and how an organization can overcome such a condition and achieve a workplace of high diversity. That is: men can afford to respond to higher salary and other related rewards in exchange of accepting the work of higher delegation and accordingly tend to have higher commitment to the company than women, even if the management has no intention to discriminate against female employees. Namely, an organization may have to more aware of barriers women face, otherwise women who seek for professional careers have to choose one of two alternatives: abandoning careers or adapting to such reality. If more and more women choose the latter, the society may lead to a long-term failure to change the masculine values (Miller, 2004). Although there are many companies who took a positive step towards embracing diversity management by providing equal opportunity and treatment between men and women in employment, the result of this research tells us that adopting the same personnel evaluation systems or giving equal power and authority to them may not be enough for realizing a sustainable gender-balanced workplace.

Furthermore, under the globalization and fierce competitive environment nowadays, if a company intends to maximize human potentials to achieve business aspirations strengthening its masculine system by introducing the result-based human resource management from a short-term viewpoint without enough care for women, the key positions will be further dominated by men by the mechanism revealed in this research. Accordingly, it is much desirable to design and propose more various working styles to promote employment of women in key positions without sacrificing their traditional roles and off course without lowering the corporate competitive power. For example, realization of a more flexible work culture that integrates work and life would counter the current rigid culture that is practiced by many organizations (Ismail \& Ibrahim, 2008).

Second, delegation-free rewards, namely, satisfaction with other treatments, fatigue, supervisor support, co-worker support, training provision and role clarity, show no significant difference between men and women on association with OC. These results imply that if a company employs these rewards as the main tools to enhance employees' OC, the company can at least maintain its gender diversity level without deterioration because they are associated with OC of both genders to the same extent, although each effect may be smaller than delegation-related rewards. The policies a company could employ will includes flex or part time working options, child care facilities, extended maternity leave, etc (Ismail \& Ibrahim, 2008). For the implementation of these policies with full effect, understanding and supports from male bosses or colleagues will be important so that women could apply more flex time systems, providing opportunities of necessary trainings will be indispensable so that women could replace the roles and positions of men, and role clarification will be also essential so that women may avoid excessive workloads. 
Third, the result shows that fatigue is not correlated to OC for both genders. Off course, it should be considered that fatigue itself could have an effect to lower OC, but at the same time it is considered that fatigue could have another effect to function adversely if an employee perceives workloads as the investment to organization (Meyer \& Allen, 1997). Accordingly, we may possibly understand that this neutral relation between fatigue and OC is caused by cancelation of these effects each other. Another considerable reason is that the sample of this survey is employees of Japanese companies who may take care of employees' health conditions well. So, if the lowering effects come to exceed enhancing effects by providing excessive workloads or poor health controls to the employees, their OC is considered to decrease. In such a case, female employees' OC may more easily go down in a workplace dominated by men and masculine culture who do not admit flexible work styles. Off course, needless to say, employees' health control is necessary to be implemented irrespective of its relation with OC and genders on humanitarian grounds.

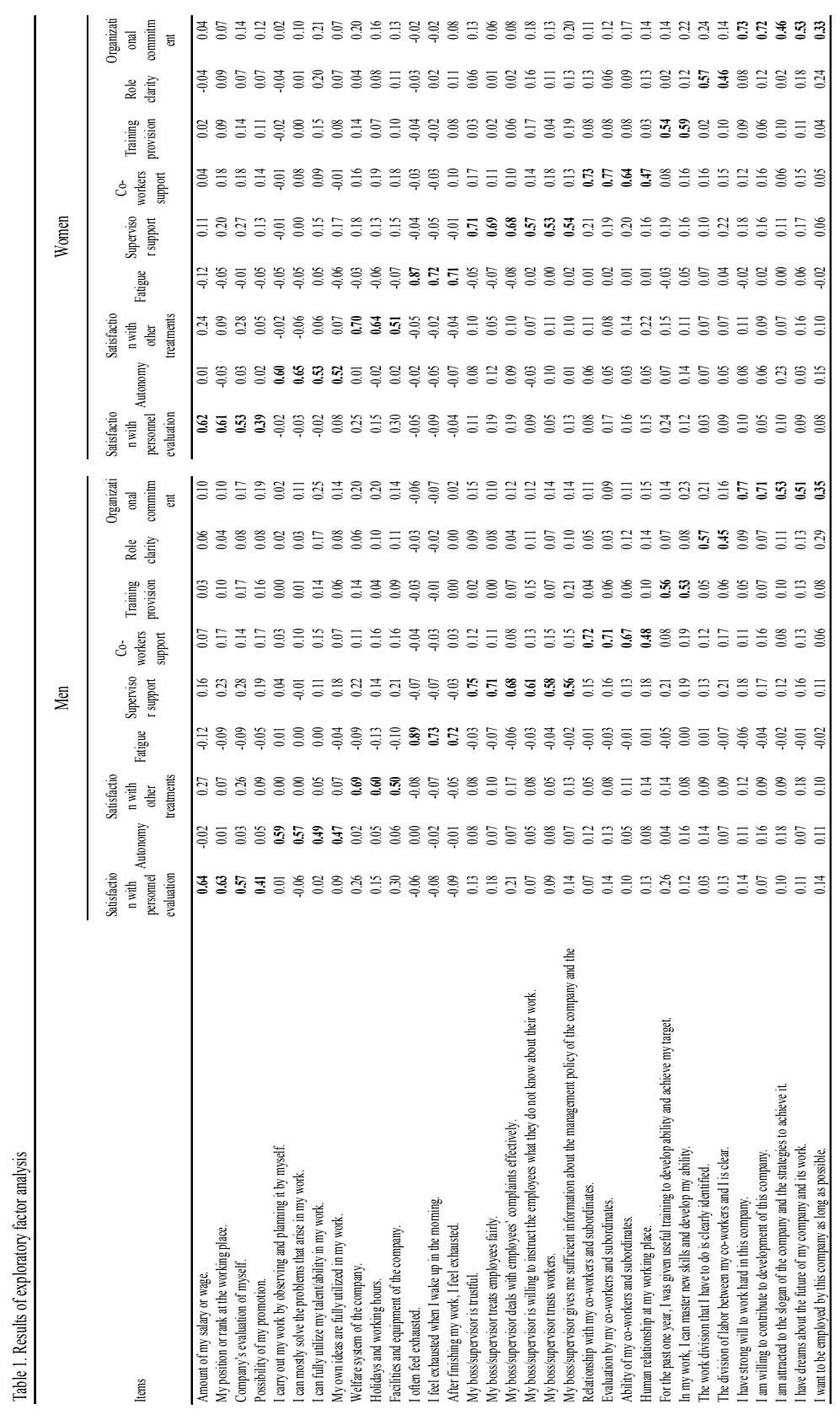




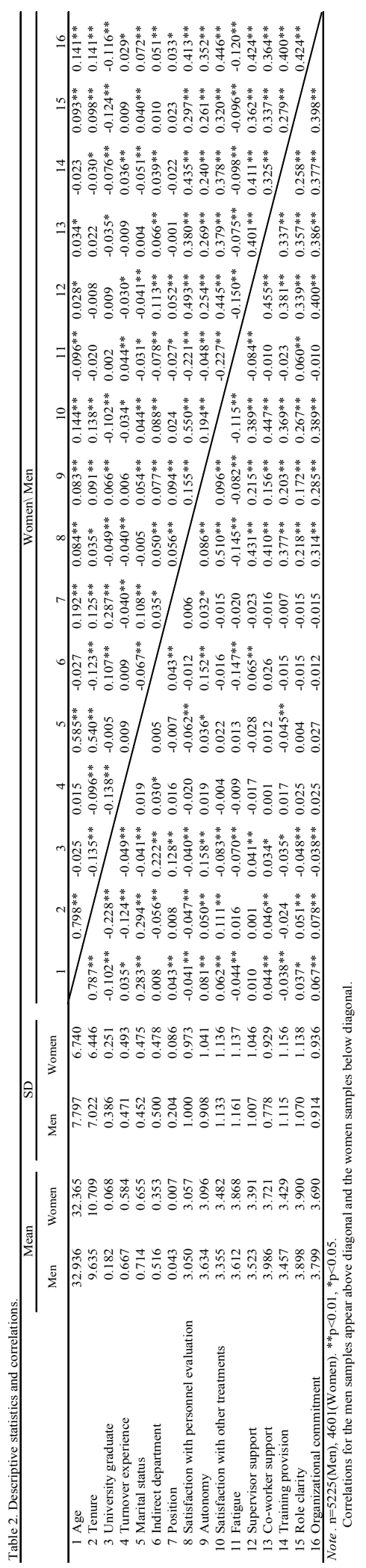


Table 3. Results of Hierarchical Analyses.

Organizational commitment

(Men and Women, $\mathrm{n}=9,826$ )

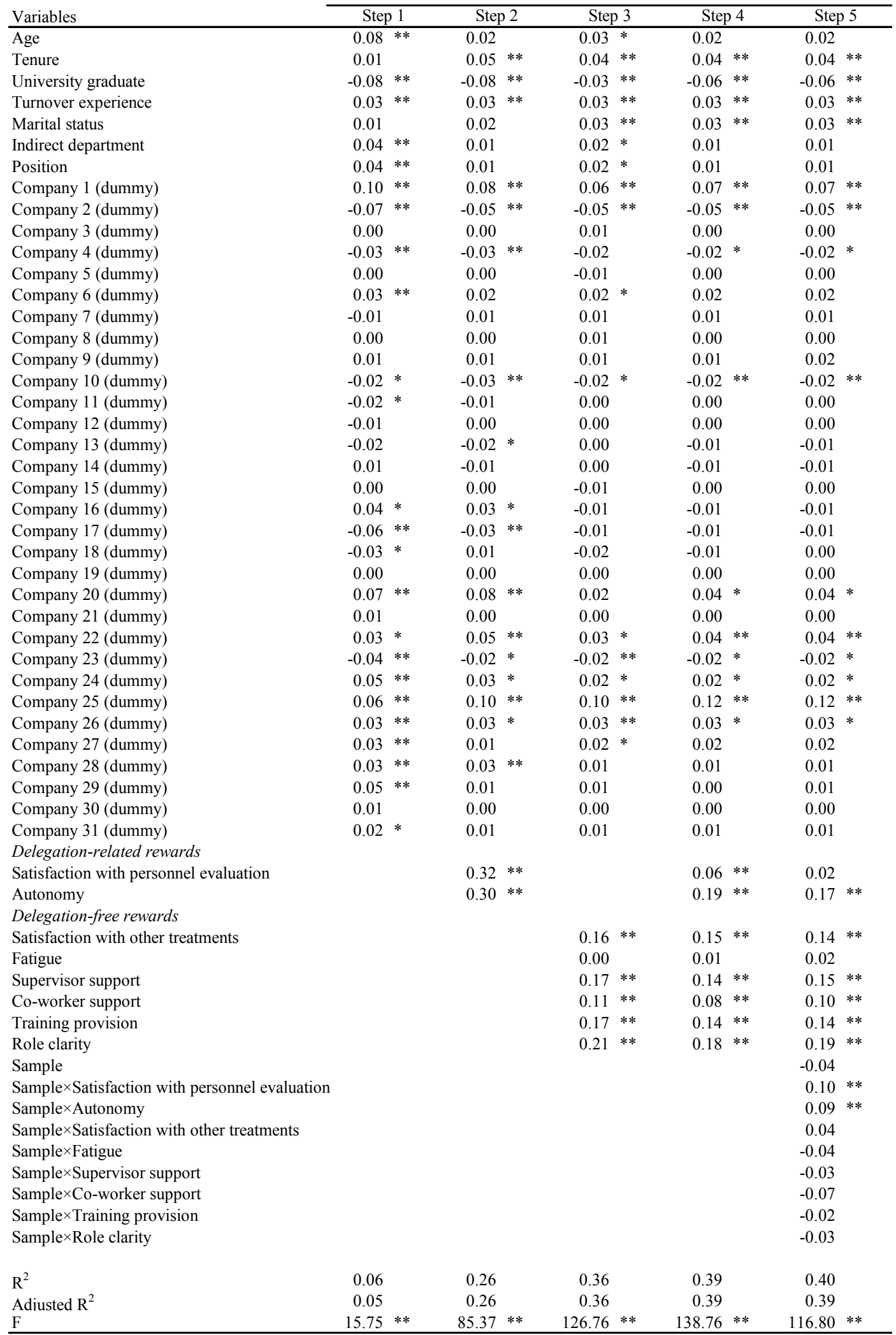

Note. ${ }^{*}$ Significance at the $5 \%$ level; **Significance at the $1 \%$ level. 


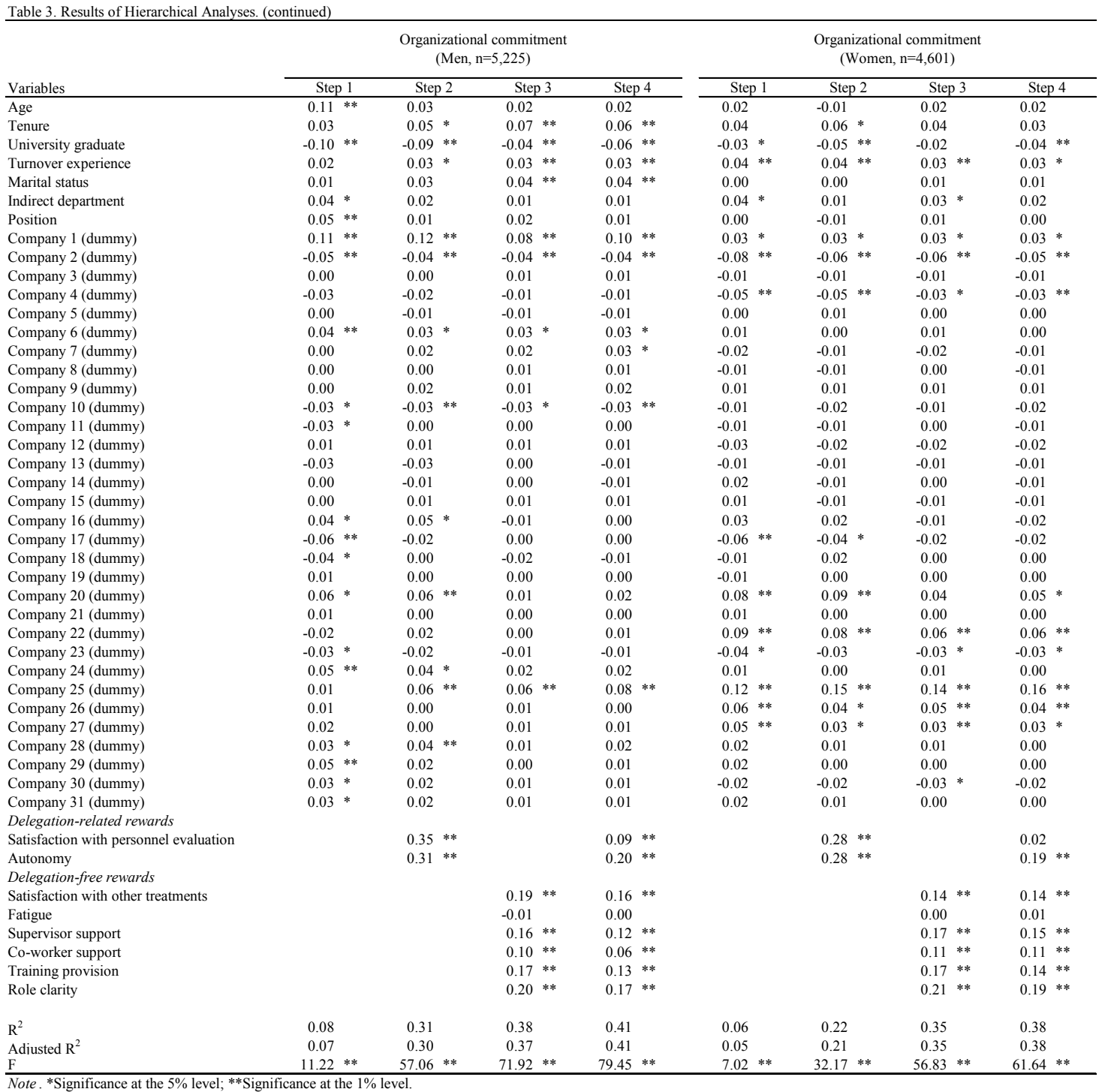

\section{Study Limitations and Suggestions for Future Research}

There are five significant limitations on this research. The first one is applicability of the result of this research. It is pointed out that the Japanese companies found it easier to operate in Malaysia than in some other Southeast Asian countries because of the similar cultural and social values of Malaysia and Japan, such as the belief that women are expendable in the workforce (Hutchings, 2000). Actually, both Malaysia and Japan rank among the countries of largest gender inequality (World Economic Forum, 2016). Accordingly, the main achievement of this research, i.e. gender difference in the strength of relation between delegation-related rewards and OC boost man-dominated workplace, may not be applicable to other kind of corporations in other nations which attain higher gender equalities.

The second limitation of this research is of applicability to the policies. Although this research proposed how a corporation can enhance OC of women in line with the recent world trend for women utilization, unfortunately, private companies, including Japanese companies and other MNCs, may not have as high desire to employ women as the Malaysian government intend. Actually, it is said that MNCs do little to transfer equity practices from the home country to the host country because MNCs employ equity practices in the developed world due merely to legislative requirements (Hutchings, 2000). Furthermore, broad research has shown that MNCs may be advantaged by operating in a socio-cultural environment which promotes the use of young, unskilled female workers in short-term, replaceable positions (International Labour Organisation, 1998; Korabik, 1993; Lim, 1993). So, the government should take the initiative on this matter and establish rules and regulations for the removal of barriers women face to achieve a condition of high diversity, although MNCs also should employ 
uniformity in utilizing the same policies in home and host countries wherever possible.

The third one is of survey targets. Comparing the proportion of management, it is $4.3 \%$ for men and $0.7 \%$ for women. Although this research compared men and women without taking into account this difference fully, different results may be shown if the targets are limited to managerial or non-managerial staffs only.

The fourth one is about reliability. This study used self-report data from single respondents, which may have resulted in common method bias. Future research might consider the inclusion of supervisor-rated scales to reduce common method bias and remedy the weakness of the present study design.

The last one is about coverage for comparison. The study here treats Malays and did not treat other ethnic groups such as Chinese, Indians, etc. which dominate approximately $40 \%$ of citizens in Malaysia. Comparison studies between the three major ethnic groups could have perhaps strengthened some aspects of this current study.

\section{References}

Aghashahi, B., Davarpanah, A., Omar, R., \& Sarli, M. (2013). The relationship between leadership style and organizational commitment: A survey in a Malaysian contract centre. Interdisciplinary Journal of Research in Business, 2(11), 1-7. from https://www.academia.edu/4391750/The_Relationship_between_Leadership_Style_and_Organizational_Co mmitment_a_survey_in_a_Malaysian_Contact_Centre

Aiken, L. S., \& West, S. G. (1991). Multiple regression: Testing and interpreting interactions. Thousand Oaks, CA: Sage.

Allen, N. J., \& Meyer, J. P. (1990). The measurement and antecedents of affective, continuous, and normative commitment to the organization. Journal of Occupational Psychology, 63(1), 252-276. https://dx.doi.org/10.1111/j.2044-8325.1990.tb00506.x

Antal, A. B., \& Izraeli, D. N. (1993). A global comparison of women in management: Women managers in their homelands and as expatriates. Sage, Thousand Oaks, CA.

Barrett, A., \& O'Connell, P. J. (2001). Does training generally work? The returns to in-company training. Industrial \& Labor Relations Review, 54(3), 647-662. http://dx.doi.org/10.2307/2695995

Bashir, N., \& Long, C. S. (2015). The relationship between training and organizational commitment among academicians in Malaysia. Journal of Management Development, 34(10), 1227-1245. http://dx.doi.org/10.1108/JMD-01-2015-0008

Beukhof, G., De Jong, M. J., \& Nijhof, W. J. (1998). Employee commitment in changing organization: An exploration. Journal of European Industrial Training, 22(6), 243-248. http://dx.doi.org/10.1108/03090599810224701

Buck, J. M., \& Watson, J. L. (2002). Retaining staff employees: The relationship between human resource management strategies and organizational commitment. Innovative Higher Education, 26(3), 175-193. http://dx.doi.org/10.1023/A:1017916922194

Carli, L. L. \& Eagly, A. H. (2001). Gender, hierarchy, and leadership: an introduction. Journal of Social Issues, 57(4), 629-636. http://dx.doi.org/10.1111/0022-4537.00232

Cecilia, N. C., \& Shanthi, T. (1999). Women and work in information age. In Ismail, M., \& Ahmad, A. (Eds.), Women and work: Challenges in industrializing nations. ASEAN Academic Press, London.

Charles, N., \& Davies, C. A. (2000). Cultural stereotypes and gendering of senior management. Sociological Review, 48(4), 544-567. http://dx.doi.org/10.1111/1467-954X.00232

Curran, C. R. (2001). Getting on board. Nursing Economics, 19(1), 2-5.

Eagly, A. H., \& Johannesen-Schmidt, M. C. (2001). The leadership styles of women and men. Journal of Social Issues, 57(4), 781-797. http://dx.doi.org/10.1111/0022-4537.00241

Eisenberger, R., Huntington, R., Hutchison, S., \& Sowa, D. (1986). Perceived organizational support. Journal of Applied Psychology, 71, 500-507. http://dx.doi.org/10.1037/0021-9010.71.3.500

Elizur, D., \& Koslowsky, M. (2001). Value and organizational commitment. International Journal of Manpower, 22(7), 595-599. http://dx.doi.org/10.1108/01437720110408967

Govindasamy, M. (2009). A Study on Factors Affecting Affective Organizational Commitment among Knowledge Workers in Malaysia (Unpublished doctoral dissertation). University of Malaya, Kuala Lumpur, Malaysia. 
Grijns, M., \& Velzen, V. A. (1993). Working Women: Differentiation and Marginalisation. In Manning, C., \& Canberra, J. H. (Eds.), Indonesia Assessment 1993. Labour: Sharing in the Benefits of Growth? Australian National University Press.

Haar, J. M., \& Spell, C. S. (2004). Programme knowledge and value of work-family practices and organizational commitment. International Journal of Human Resource Management, 15(6), 1040-1054. http://dx.doi.org/10.1080/09585190410001677304

Hartmann, L.C. (2000). Organizational commitment: A multi-method scale analysis and test of effects. International Journal of Organizational Analysis, 8(1), 89-108. http://dx.doi.org/10.1108/eb028912

Hughes, W. (2004). Getting on the Right Track at Work. Times Edition, Shah Alam, Malaysia.

Hutchings, K. (2000). Cultural norms and gender inequality in Malaysia. Race, Gender \& Class, 7(2), 122-148. Retrieved from https://www.jstor.org/stable/41674940?seq=1\#page_scan_tab_contents

Ibrahim, I. I., \& Boerhaneoddin, A. (2010). Is job satisfaction mediating the relationship between compensation structure and organizational commitment? A study in the Malaysian power utility. Journal of Global Business and Economics, 1(1), 43-61. Retrieved from https://ideas.repec.org/s/grg/01 biss.html

International Economy and Work Research Institute. (1996). ONION2 Sankagata Soshiki toshiteno Rodo Kumiai no Saisei: Syakai Sinrigaku karano Teigen (ONION2: Renovation of Trade Union as an Organization for Participation and Engagement). Osaka, Japan. (Japanese)

International Labour Organisation (1998). Will the glass ceiling ever be broken? ILO Magazine 23, Geneva: ILO.

Islam, R., \& Ismail, A. Z. H. (2008). Employee motivation: A Malaysian perspective. International Journal of Commerce and Management, 18(4), 344-362. http://dx.doi.org/10.1108/10569210810921960

Ismail, M., \& Ibrahim, M. (2008). Barriers to career progression faced by women: Evidence from a Malaysian multinational oil company. Gender in Management: An International Journal, 23(1), 51-66. http://dx.doi.org/10.1108/17542410810849123

Juhdi, N., Pa'wan, F., \& Hansaram, R. M. K. (2013). HR Practices and Turnover Intention: The Mediating Roles of Organizational Commitment and Organizational Engagement in a Selected Region in Malaysia. The International Journal of Human Resource Management, 24(15), 3002-3019. http://dx.doi.org/10.1080/09585192.2013.763841

Karim, N. H. A (2010). The impact of work related variables on librarians' organizational commitment and job satisfaction. Malaysian Journal of Library \& Information Science, 15(3), 149-163. Retrieved from http://icmsm2009.um.edu.my/filebank/articles/2779/no.10.pdf

Kee, L. B., Ahmad, R. B. \& Abdullah, A. M. (2016). Relationship between financial compensation and organizational commitment among Malaysian bank workers. Asian Business Research, 1(1), 75-85. https://dx.doi.org/10.20849/abr.v1i1.29

Kokubun, K. (2006). Globalization and Industrial Reallocation: How to motivate Malaysian workers. Paper presented at the 3rd International Globalization Studies Network (GSN) Conference, Universiti Kebangsaan Malaysia.

Kokubun, K. (2017). Organizational commitment and rewards in Thailand, with comparison between university graduates and others. Asian Social Science, 13(6). https://doi.org/10.5539/ass.v13n6p1

Korabik, K. (1993). Managerial women in the People's Republic of China. International Studies of Management and Organisation, 23(4):47-56. http://dx.doi.org/10.1080/00208825.1993.11656618

Ledet, L. M., \& Henley, T. B. (2000). Perceptions of women's power as a function of position within an organization, The Journal of Psychology, 134(5), 515-526. http://dx.doi.org/10.1080/00223980009598233

Leow, K. H., \& Khong, K. W. (2009). Organizational commitment: The study of organizational justice and leader member exchange (LMX) among auditors in Malaysia. International journal of business and information, 4(2), 161-198. Retrieved from http://ijbi.org/ijbi/article/view/42

Lim, L.L. (1993). The feminization of labour in the Asia-Pacific Rim countries: From contributing to economic dynamism to bearing the brunt of structural adjustments. In Ogawa, N., Jones, G. W., \& Williamson, J. G. (Eds), Human Resources in Development along the Asia-Pacific Rim. Singapore: Oxford University Press.

Lo, M.C., Ramayah, T., \& Min, H.,W. (2009). Leadership styles and organizational commitment: A test on 
Malaysia manufacturing industry. African Journal of Marketing Management, 1(6), 133-139. Retrieved from http://www.academicjournals.org/journal/AJMM/article-full-text-pdf/35C40141998

Maimunah, I., \& Ahmad, A. (1999). Women and work: Challenges in Industrializing Nations. ASEAN Academic Press, London.

Maimunah, I., \& Roziah, M. R. (2006). High-flying women academics: A question of career mobility. Pelanduk Publications, Subang Jaya.

Manshor, A. T., Fontaine, R., \& Chong, S. C. (2003). Occupational stress among managers: A Malaysian survey. Journal of Managerial Psychology, 18(6), 622-628. http://dx.doi.org/10.1108/02683940310494412

Mansor, N. (1994). Women managers in Malaysia: Their mobility and challenges. Competitive Frontiers: Women Managers in a Global Economy, 101-113.

Marmaya, N. H., Hitam, M., Torsiman, N. M., \& Balakrishnan, B. K. P. D. (2011). Employees' perceptions of Malaysian managers' leadership styles and organizational commitment. African Journal of Business $\begin{array}{llll}\text { Management, } & 5(5), & \text { Retrieved } & \text { from }\end{array}$ http://www.academicjournals.org/journal/AJBM/article-full-text-pdf/690523718444

Marsden, P. V., Kalleberg, A. L. and Cook, C. R. (1993). Gender differences in organizational commitment: Influences of work positions and family roles. Work and Occupations, 20(3), 368-390. http://dx.doi.org/10.1177/0730888493020003005

Maskell-Prets, M., \& Hopkins, W. E. (1997). Women in engineering: Toward a barrier-free work environment. Journal of Management in Engineering, 13(1). http://dx.doi.org/10.1061/(ASCE)0742-597X(1997)13:1(32)

Mason, E. S. (1995). Gender differences in job satisfaction. Journal of Social Psychology, 135(2), 143-151. http://dx.doi.org/10.1080/00224545.1995.9711417

Mathieu, J. E., \& Zajac, D. M. (1990). A review and meta-analysis of the antecedents, correlates, and consequences of organizational commitment. Psychological Bulletin, 108(2), 171-94. http://dx.doi.org/10.1037/0033-2909.108.2.171

Matsui, Y. (1987). Women workers in modern factories: Impact of Japanese-style management. In Matsui, Y. (Ed.). Women's Asia. London: Zed Books.

Mattis, M. C. (2002). Advancing women's career: Research and practice. Blackwell Publishers, London.

Mellor, S., Mathieu, J. E., \& Swim, J. K. (1994). Cross-level analysis of the influence of local union structure on women's and men's commitment. Journal of Applied Psychology, 79(2), 203-210. http://dx.doi.org/10.1037/0021-9010.79.2.203

Meyer, J. P., \& Allen, N. J. (1997). Commitment in the workplace: Theory, research, and application. Sage Publications.

Meyer, J. P., Stanley, D. J., Herscovitch, L., \& Topolnysky, L. (2002). Affective, continuous, and normative commitment to the organization: A meta-analysis of antecedents, correlates, and consequences. Journal of Vocational Behavior, 61, 20-52. http://dx.doi.org/10.1006/jvbe.2001.1842

Milfont, T. L., \& Fischer, R. (2010). Testing measurement invariance across groups: Applications in cross-cultural research. International Journal of Psychological Research, 3, 111-121.

Miller, E. G. (2004). Frontier masculinity in the oil industry: The experience of women engineers. Gender, Work \& Organization, 11(1), 47-73. http://dx.doi.org/10.1111/j.1468-0432.2004.00220.x

Mottaz, C. J. (1985). The relative importance of intrinsic and extrinsic rewards as determinants of work $\begin{array}{llll}\text { satisfaction. The } & \text { Sociological } & \text { Quarterly, } & \text { 26(3), }\end{array}$ http://dx.doi.org/10.1111/j.1533-8525.1985.tb00233.x

Mowday, R. T., Porter, L. W., \& Steers, R. M. (1982). Employee-organization linkages: The psychology of commitment, absenteeism and turnover. New York, NY: Academic Press.

Newman, A., Thanacoody, R., \& Hui, W. (2011). The impact of employee perceptions of training on organizational commitment and turnover intentions: A study of multinationals in the Chinese service sector. International Journal of Human Resource Management, 22(8), 1765-1787. http://dx.doi.org/10.1080/09585192.2011.565667

Normala, D. (2010). Investigating the relationship between quality of work life and organizational commitment amongst employees in Malaysian firms. International Journal of Business and Management, 5(10), 75. 
http://dx.doi.org/10.5539/ijbm.v5n10p75

Porter, L. W., \& Lawler, E. E. (1968). Managerial attitudes and performance. Homewood, IL: Dorsey Press.

Rachagan, S., Tong, J., Terpstra, R., \& Mahenthiran, S. (2014). CEOs organizational commitment and firm performance: Malaysian evidence. International Business and Management, 8(2), 1-13. http://dx.doi.org/10.3968/\%25x

Ramli, A., \& Desa, N., M. (2013). The relationship between servant leadership and organizational commitment: The Malaysian perspectives. Handbook on the Economics, Finance and Management Outlooks, 312-324.

Rosser, S. V. (2004). Using power to advance: Institutional barriers identified by women scientists and engineers. NWSA Journal, 16(1), 50-78. http://dx.doi.org/10.2979/NWS.2004.16.1.50

Roziah, M. R., \& Maimunah, I. (2007). Gender difference in management style. Journal of International Management Studies, 2(1), 93-102. http://dx.doi.org/10.1108/09649420110395728

Salleh, R., Nair, M. S., \& Harun, H. (2012). Job satisfaction, organizational commitment, and turnover intention: A case study on employees of a retail company in Malaysia. International Journal of Social, Behavioral, Educational, Economic, Business and Industrial Engineering, 6(12), 3429-3436. http://waset.org/publications/8349/job-satisfaction-organizational-commitment-and-turnover-intention-a-cas e-study-on-employees-of-a-retail-company-in-malaysia

Samad, S. (2007). Assessing the effects of job satisfaction and psychological contract on organizational commitment among employees in Malaysian SMEs. The 4th SMEs in a Global Economy Conference 2007.

Savery, L. K., \& Syme, P. D. (1996). Organizational commitment and hospital pharmacists. Journal of Management Development, 15(1), 14-22. http://dx.doi.org/10.1108/02621719610107773

Siraj, M. (1984). Islamic attitudes to female employment in industrializing economies: Some notes from Malaysia. In G. W. Jones (Ed), Women in the urban and industrial workforce. Southeast and East Asia. Canberra: Australian National University Press.

Steers, R.M. (1977). Antecedents and outcomes of organizational commitment. Administrative Science Quarterly, 22(1), 46-56. http://dx.doi.org/10.2307/2391745

United Nations Malaysia (2016). Millennium Development Goals Report 2015. Kuala Lumpur, Malaysia. Retrieved from http://www.my.undp.org/content/malaysia/en/home/library/mdg/malaysia-millennium-development-goals-2 015-report-.html

Vinas, T. (2003). A place at the table. Industry Week/IW, 252(7), 22.

White, M. C. (1990). Improving the welfare of women factory workers: Lessons from Indonesia. International Labour Review. 129(1), 121-131.

Wiersma, U. J. (1990). Gender differences in job attribute preferences: work-home role conflict and job level as mediating variables. Journal of Occupational and Organizational Psychology, 63, 231-44. http://dx.doi.org/10.1111/j.2044-8325.1990.tb00524.x

Williams, J. C., \& Cooper, H. C. (2004). The public of motherhood. Journal of Social Issue, 60(4), 849-865. http://dx.doi.org/10.1111/j.0022-4537.2004.00390.x

Women for Women Foundation (Asia). (1990). Women managers in Southeast Asia. Kuala Lumpur.

World Economic Forum (2016), The Global Gender Gap Report 2016. Retrieved from http://reports.weforum.org/global-gender-gap-report-2016/ 
Appendix. Demographic Information

\begin{tabular}{|c|c|c|c|c|c|c|c|c|c|c|}
\hline & \multicolumn{2}{|c|}{ Gender } & \multirow{2}{*}{ Total } & \multicolumn{5}{|c|}{ Age } & \multirow[b]{2}{*}{ Total } & \\
\hline & Male & Female & & $\begin{array}{c}\text { Belowr } 20 \\
\text { years old }\end{array}$ & $20-29$ & $30-39$ & $40-49$ & $\begin{array}{l}50 \text { years old } \\
\text { and above }\end{array}$ & & \\
\hline \multirow{2}{*}{ Male } & 5,225 & 0 & 5,225 & 44 & 1,906 & 2,178 & 990 & 107 & 5,225 & \\
\hline & $100.0 \%$ & $0.0 \%$ & $100.0 \%$ & $0.8 \%$ & $36.5 \%$ & $41.7 \%$ & $18.9 \%$ & $2.0 \%$ & $100.0 \%$ & \\
\hline \multirow{2}{*}{ Female } & 0 & 4,601 & 4,601 & 39 & 1,652 & 2,155 & 733 & 22 & 4,601 & \\
\hline & $0.0 \%$ & $100.0 \%$ & $100.0 \%$ & $0.8 \%$ & $35.9 \%$ & $46.8 \%$ & $15.9 \%$ & $0.5 \%$ & $100.0 \%$ & \\
\hline \multirow{4}{*}{ Total } & 5,225 & 4,601 & 9,826 & 83 & 3,558 & 4,333 & 1,723 & 129 & 9,826 & \\
\hline & $53.2 \%$ & $46.8 \%$ & $100.0 \%$ & $0.8 \%$ & $36.2 \%$ & $44.1 \%$ & $17.5 \%$ & $1.3 \%$ & $100.0 \%$ & \\
\hline & \multicolumn{5}{|c|}{ Tenure } & \multicolumn{3}{|c|}{ Turnover experience } & \multirow[b]{2}{*}{ Total } & \\
\hline & Below 2 year & $2-5$ year & $6-9$ years & $10-19$ years & $\begin{array}{c}20 \text { years and } \\
\text { above }\end{array}$ & Total & $\begin{array}{c}\text { Have } \\
\text { experience }\end{array}$ & $\begin{array}{c}\text { Have no } \\
\text { experience }\end{array}$ & & \\
\hline \multirow{2}{*}{ Male } & 756 & 1,101 & 735 & 2,168 & 465 & 5,225 & 3,483 & 1,742 & 5,225 & \\
\hline & $14.5 \%$ & $21.1 \%$ & $14.1 \%$ & $41.5 \%$ & $8.9 \%$ & $100.0 \%$ & $66.7 \%$ & $33.3 \%$ & $100.0 \%$ & \\
\hline \multirow{2}{*}{ Female } & 387 & 800 & 770 & 2,292 & 352 & 4,601 & 2,689 & 1,912 & 4,601 & \\
\hline & $8.4 \%$ & $17.4 \%$ & $16.7 \%$ & $49.8 \%$ & $7.7 \%$ & $100.0 \%$ & $58.4 \%$ & $41.6 \%$ & $100.0 \%$ & \\
\hline \multirow{4}{*}{ Total } & 1,143 & 1,901 & 1,505 & 4,460 & 817 & 9,826 & 6,172 & 3,654 & 9,826 & \\
\hline & $11.6 \%$ & $19.3 \%$ & $15.3 \%$ & $45.4 \%$ & $8.3 \%$ & $100.0 \%$ & $62.8 \%$ & $37.2 \%$ & $100.0 \%$ & \\
\hline & \multicolumn{8}{|c|}{ Educational background } & \multirow[b]{2}{*}{ Total } & \\
\hline & $\begin{array}{l}\text { Lower } \\
\text { Secondary } \\
\text { School }\end{array}$ & $\begin{array}{c}\text { Upper } \\
\text { Secondary } \\
\text { School }\end{array}$ & $\begin{array}{l}\text { Specialized } \\
\text { College }\end{array}$ & $\begin{array}{c}\text { College/ } \\
\text { Vocational }\end{array}$ & University & $\begin{array}{l}\text { Graduate } \\
\text { School }\end{array}$ & $\begin{array}{c}\text { In the middle } \\
\text { of school } \\
\text { years }\end{array}$ & Others & & \\
\hline \multirow{2}{*}{ Male } & 1,543 & 860 & 761 & 896 & 846 & 103 & 13 & 203 & 5,225 & \\
\hline & $29.5 \%$ & $16.5 \%$ & $14.6 \%$ & $17.1 \%$ & $16.2 \%$ & $2.0 \%$ & $0.2 \%$ & $3.9 \%$ & $100.0 \%$ & \\
\hline \multirow{2}{*}{ Female } & 2,606 & 1,185 & 161 & 209 & 273 & 38 & 5 & 124 & 4,601 & \\
\hline & $56.6 \%$ & $25.8 \%$ & $3.5 \%$ & $4.5 \%$ & $5.9 \%$ & $0.8 \%$ & $0.1 \%$ & $2.7 \%$ & $100.0 \%$ & \\
\hline \multirow{4}{*}{ Total } & 4,149 & 2,045 & 922 & 1,105 & 1,119 & 141 & 18 & 327 & 9,826 & \\
\hline & $42.2 \%$ & $20.8 \%$ & $9.4 \%$ & $11.2 \%$ & $11.4 \%$ & $1.4 \%$ & $0.2 \%$ & $3.3 \%$ & $100.0 \%$ & \\
\hline & & Marital status & & \multirow[b]{2}{*}{ Total } & \multicolumn{2}{|c|}{ Department } & \multicolumn{3}{|c|}{ Position } & \multirow[b]{2}{*}{ Total } \\
\hline & Single & Married & Others & & $\begin{array}{c}\text { Direct } \\
\text { department }\end{array}$ & $\begin{array}{c}\text { Indirect } \\
\text { department }\end{array}$ & Total & $\begin{array}{l}\text { Managerial } \\
\text { position }\end{array}$ & $\begin{array}{c}\text { Non- } \\
\text { managerial } \\
\text { position }\end{array}$ & \\
\hline \multirow{2}{*}{ Male } & 1,440 & 3,729 & 56 & 5,225 & 2,528 & 2,697 & 5,225 & 227 & 4,998 & 5,225 \\
\hline & $27.6 \%$ & $71.4 \%$ & $1.1 \%$ & $100.0 \%$ & $48.4 \%$ & $51.6 \%$ & $100.0 \%$ & $4.3 \%$ & $95.7 \%$ & $100.0 \%$ \\
\hline \multirow{2}{*}{ Female } & 1,397 & 3,014 & 190 & 4,601 & 2,979 & 1,622 & 4,601 & 34 & 4,567 & 4,601 \\
\hline & $30.4 \%$ & $65.5 \%$ & $4.1 \%$ & $100.0 \%$ & $64.7 \%$ & $35.3 \%$ & $100.0 \%$ & $0.7 \%$ & $99.3 \%$ & $100.0 \%$ \\
\hline Total & 2,837 & 6,743 & 246 & 9,826 & 5,507 & 4,319 & 9,826 & 261 & 9,565 & 9,826 \\
\hline rotal & $28.9 \%$ & $68.6 \%$ & $2.5 \%$ & $100.0 \%$ & $56.0 \%$ & $44.0 \%$ & $100.0 \%$ & $2.7 \%$ & $97.3 \%$ & $100.0 \%$ \\
\hline & & & & St & tes & & & & & \\
\hline & Selangor & Penang & Johor & Kedah & Kelantan & Perak & $\begin{array}{c}\text { Negeri } \\
\text { Sembilan }\end{array}$ & $\begin{array}{l}\text { Kuala } \\
\text { Lumpur }\end{array}$ & Total & \\
\hline Male & 1,791 & 863 & 1,326 & 467 & 590 & 85 & 8 & 95 & 5,225 & \\
\hline Male & $34.3 \%$ & $16.5 \%$ & $25.4 \%$ & $8.9 \%$ & $11.3 \%$ & $1.6 \%$ & $0.2 \%$ & $1.8 \%$ & $100.0 \%$ & \\
\hline & 991 & 850 & 1,455 & 500 & 559 & 179 & 3 & 64 & 4,601 & \\
\hline Female & $21.5 \%$ & $18.5 \%$ & $31.6 \%$ & $9.5 \%$ & $10.6 \%$ & $3.9 \%$ & $0.1 \%$ & $1.4 \%$ & $97.0 \%$ & \\
\hline Total & 2,782 & 1,713 & 2,781 & 967 & 1,149 & 264 & 11 & 159 & 9,826 & \\
\hline lotal & $28.3 \%$ & $17.4 \%$ & $28.3 \%$ & $9.1 \%$ & $10.8 \%$ & $2.7 \%$ & $0.1 \%$ & $1.6 \%$ & $98.3 \%$ & \\
\hline
\end{tabular}

\section{Copyrights}

Copyright for this article is retained by the author(s), with first publication rights granted to the journal.

This is an open-access article distributed under the terms and conditions of the Creative Commons Attribution license (http://creativecommons.org/licenses/by/4.0/). 